\title{
VARIATION IN CHARACTERS AFFECTING FITNESS BETWEEN RADIATE AND NON-RADIATE MORPHS IN NATURAL POPULATIONS OF GROUNDSEL (SENECIO VULGARIS L.)
}

\author{
G. S. OXFORD and T. ANDREWS* \\ Department of Biology, University of York, Heslington, York Y01 5DD
}

Received 29.xi.76

\section{SUMMARY}

Two characters which might be expected to affect relative fitness have been studied in two capitulum morphs of groundsel, Senecio vulgaris L. In natural populations the radiate morph $(T r T r)$ produces more capitula per plant (six out of eight populations) and more seeds per capitulum (six out of six populations) than the non-radiate morph $\left(T_{n} T_{n}\right)$. Given that these potential fitness characters vary between morphs, the suggestion by Hull (1976), that the increase in the $T r$ allele in populations in central Scotland is merely a result of " introgressive pressure" from $S$. squalidus, is considered most unlikely.

\section{INTRODUCTION}

RENEWED interest has recently been shown in the origin and distribution of the radiate form of groundsel (Senecio vulgaris L.) (Hull, 1974a, b, 1975, 1976; Monaghan and Hull, 1975; Richards, 1975). The evidence available suggests that the radiate allele $(T r)$ may have been introduced into $S$. vulgaris populations from Oxford ragwort ( $S$. squalidus L.) via interspecific hybrids. The three flower morphs of groundsel, non-radiate, intermediate and radiate ( $T n T n, T n T r$ and $\operatorname{Tr} T r$ respectively) are readily distinguishable by the absence or, if present, the length of the ray-florets (Richards, 1975).

Hull $(1975,1976)$ has presented data for populations near Edinburgh in central Scotland indicating that where $S$. vulgaris coexists with $S$. squalidus the frequency of the radiate morph has increased with time. To the west, around Glasgow, $S$. squalidus is rare and here the frequencies of the radiate and non-radiate morphs of $S$. vulgaris have remained stable. Hull (1976) argues that the increase in the frequency of the radiate form in the eastern area is more likely to be the result of repeated introgression with $S$. squalidus than of selection favouring the $\mathrm{Tr}$ allele in $S$. vulgaris.

Richards (1975), in a detailed laboratory study of $S$. vulgaris, concluded that although the non-radiate genotype ( $T n T n)$ showed a faster growth rate, produced more leaves and flowered sooner than the radiate genotype $(\operatorname{Tr} T r)$, the radiate form developed more capitula per plant and the capitula contained more seeds relative to the non-radiate form.

If it can be shown that these characters, which will presumably affect fitness, also vary in the wild, it would make the passive introgression hypothesis of Hull (1976) much less likely as an explanation of the increase in the frequency of the $\operatorname{Tr}$ allele in his eastern area.

* Present address: Department of Human Genetics, the University of Newcastle upon Tyne, 19 Claremont Place, Newcastle upon Tyne NE2 4AA. 


\section{Methods}

A total of nine polymorphic populations were visited between December 1974 and February 1975. At each site, all of the plants within a well defined area were scored for capitulum type and, in eight populations, the number of capitula per plant (including the number in flower, in bud and those that had already flowered) was also noted (table l). In six of the populations, two intact capitula were taken from each of 10 radiate and 10 non-radiate plants, picked at random (table 1). Intermediate plants were found in very small numbers in all these populations and are not considered further.

TABLE 1

Numbers of the three genotypes in the populations surveyed

\begin{tabular}{|c|c|c|c|c|c|c|c|c|c|}
\hline & \multirow[b]{2}{*}{ Map ref. } & \multirow{2}{*}{$\begin{array}{l}\text { Date } \\
\text { scored }\end{array}$} & \multicolumn{3}{|c|}{ Genotypes } & \multirow{2}{*}{ Total } & \multirow{2}{*}{ Freq. $T r$} & \multirow{2}{*}{ Capitula* } & \multirow{2}{*}{ Seeds* } \\
\hline & & & $\operatorname{Tr} T r$ & $\operatorname{TnTr}$ & $T n T n$ & & & & \\
\hline Selby 1 & SE 617322 & $3 / 2 / 75$ & 36 & 1 & 38 & 75 & 0.49 & + & + \\
\hline Selby 2 & SE 619323 & $3 / 2 / 75$ & 82 & 4 & 69 & 155 & 0.54 & + & + \\
\hline Mumbles 2 & SS 617881 & $9 / 2 / 75$ & 23 & 5 & 54 & 82 & 0.31 & + & + \\
\hline Barry 1 & ST 113667 & $10 / 2 / 75$ & 86 & 6 & 60 & 152 & 0.59 & + & + \\
\hline Barry 2 & ST 125680 & $10 / 2 / 75$ & 51 & 0 & 76 & 127 & 0.40 & + & - \\
\hline Barry 3 & ST 116664 & $10 / 2 / 75$ & 39 & 0 & 122 & 161 & 0.24 & + & + \\
\hline Barry 4 & ST 124678 & $10 / 2 / 75$ & 166 & 9 & 65 & 260 & 0.71 & + & - \\
\hline Barry 5 & ST 118704 & $10 / 2 / 75$ & 31 & 5 & 70 & 106 & 0.32 & + & + \\
\hline Warwick & SP 298655 & $28 / 12 / 74$ & 20 & 0 & 47 & 67 & 0.30 & - & - \\
\hline
\end{tabular}

$*+=$ Populations used in the anlysis of number of capitula per plant and number of seeds per capitulum, respectively.

\section{Results}

The mean number of capitula per plant is shown in table 2. For the analysis the number of plants of each genotype in each population was reduced to 23 using random number tables (23 being the lowest number of either genotype scored (Mumbles 2, table 1)). Analysis of variance indicated a significant effect of both genotype and site on capitulum number and also a strong genotype $\times$ site interaction (table 3 ). In most populations the radiate morph showed a higher mean number of capitula per plant than the non-radiate morph. This difference was significant in four populations and non-significant in the other two. Of the two populations in which the radiate morph had a lower fitness than the non-radiate morph, the difference was significant in one, Barry 3 (table 2).

TABLE 2

Mean number of capitula per plant

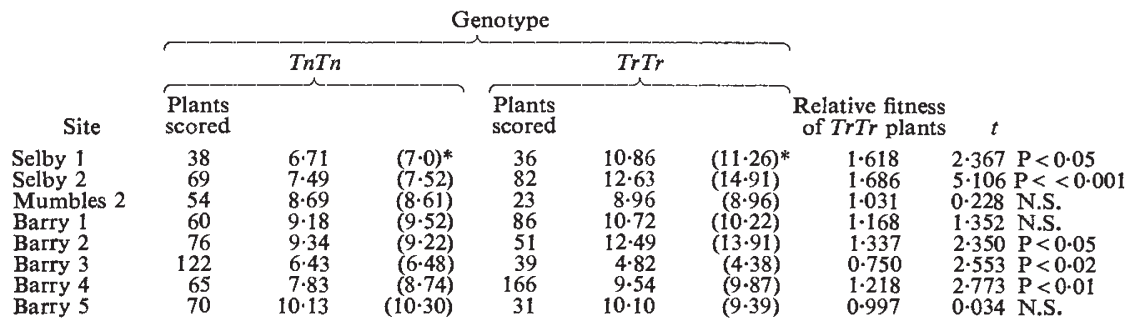

* Mean number of capitula per plant for the 23 plants used in the analysis of variance.

Relative fitness and values of $t$ are calculated using the total numbers of plants scored per popuiation. 
TABLE 3

$A N O V A R$ of the number of capitula per plant

\begin{tabular}{lrrrrr}
$\quad$ Source & d.f. & \multicolumn{1}{c}{ S.S. } & M.S. & F & \\
Subgroups & 15 & $2313 \cdot 479$ & $154 \cdot 099$ & - & \\
$\quad$ Genotypes & 1 & $344 \cdot 392$ & $344 \cdot 390$ & $10 \cdot 77$ & $\mathrm{P}<0.01$ \\
Sites & 7 & $1139 \cdot 435$ & $162 \cdot 776$ & $5 \cdot 092$ & $\mathrm{P}<0.01$ \\
$\quad$ G $\times$ S & 7 & $829 \cdot 652$ & 118.522 & 3.708 & $\mathrm{P}<0.01$ \\
Error & 352 & $11252 \cdot 174$ & 31.966 & - & \\
Total & 367 & $13565 \cdot 653$ & - & - &
\end{tabular}

TABLE 4

Mean number of seeds per capitulum

\begin{tabular}{|c|c|c|c|c|}
\hline \multirow[b]{2}{*}{ Site } & \multicolumn{2}{|c|}{ Genotype } & $\begin{array}{c}\text { Relative fitness } \\
\text { of }\end{array}$ & \multirow[b]{2}{*}{$t$} \\
\hline & $T_{n} T_{n}$ & $\operatorname{Tr} T_{r}$ & $\operatorname{Tr} T r$ plants & \\
\hline Selby 1 & $51 \cdot 40$ & $58 \cdot 05$ & $1 \cdot 13$ & $2.441 \quad \mathrm{P}<0.05$ \\
\hline Selby 2 & $45 \cdot 15$ & 62.55 & $1 \cdot 38$ & $6.812 \mathrm{P}<<0.001$ \\
\hline Mumbles 2 & $44 \cdot 35$ & $58 \cdot 00$ & $1 \cdot 31$ & $5.914 \mathrm{P}<<0.001$ \\
\hline Barry 1 & $47 \cdot 75$ & $61 \cdot 85$ & 1.29 & $6.205 \mathrm{P}<<0.001$ \\
\hline Barry 3 & $45 \cdot 35$ & $57 \cdot 15$ & $1 \cdot 26$ & $3.349 \quad \mathrm{P}<0.01$ \\
\hline Barry 5 & $42 \cdot 05$ & $62 \cdot 90$ & $1 \cdot 49$ & $6.529 \mathrm{P}<<0.001$ \\
\hline Means & $\overline{46.01}$ & 60.08 & 1.31 & \\
\hline
\end{tabular}

TABLE 5

ANOVAR of the number of seeds per capitulum

\begin{tabular}{|c|c|c|c|c|}
\hline Source & d.f. & S.S. & M.S. & $\mathrm{F}$ \\
\hline Subgroups & 11 & $6288 \cdot 63$ & $571 \cdot 694$ & - \\
\hline Genotypes & 1 & $5582 \cdot 85$ & $5582 \cdot 850$ & $96 \cdot 882$ \\
\hline Sites & 5 & $266 \cdot 53$ & $53 \cdot 306$ & 0.925 \\
\hline $\mathrm{G} \times \mathrm{S}$ & 5 & $439 \cdot 25$ & $85 \cdot 850$ & 1.525 \\
\hline Error & 108 & $6223 \cdot 52$ & $57 \cdot 625$ & - \\
\hline Total & 119 & $12512 \cdot 15$ & 一 & - \\
\hline
\end{tabular}

Table 4 gives the results of counts of seeds per capitulum as averages for each genotype in each population. For an analysis of variance the mean number of seeds per individual plant was used. The results of the analysis indicate a highly significant effect of genotype but no effect of site or a genotype $x$ site interaction (table 5). In all six populations the mean numbers of seeds per capitulum from radiate and non-radiate plants were significantly different (table 4).

\section{Discussion}

Richards (1975) showed that, in comparison to the radiate genotype, the non-radiate morph possessed vegetative traits that might be expected to influence its overall fitness; e.g. faster growth rate and shorter time to first flower. However, the results of preliminary experiments in which radiate and non-radiate groundsel were grown under crowded conditions 
(1 plant per $4 . \mathrm{cm}^{2}$ ) indicated that the radiate morph was reproductively superior, having a larger number of capitula per plant and a larger number of seed per capitulum than the non-radiate form.

Surveys of a number of natural populations confirm that the radiate morph is apparently at a reproductive advantage under most field conditions. In six out of the eight populations studied, the radiate morph had a higher number of capitula per plant than the non-radiate morph (table 2). Clearly, if there are differences in flowering time between radiate and non-radiate plants this may influence counts of the number of capitula per plant. Nevertheless, whether a real difference in capitula production or differences in flowering time have resulted in the disparity between the two genotypes, the fact remains that they are different and this difference could affect the relative fitness of the morphs.

It is worth noting that the populations with the lowest relative fitnesses of radiate plants, i.e. Mumbles 2, Barry 3 and Barry 5 (table 2) also have the lowest frequencies of the $\operatorname{Tr}$ allele (table 1), although there is no general correlation between these two parameters $(r=0.5591$, d.f. $=6, P>0 \cdot 1)$. The reasons for the variation in relative fitness of the radiate morph between sites is not clear. Other $\operatorname{Tr}$ or $T n$ alleles may be present or, if the number of capitula is determined by a locus or loci linked to that controlling capitulum type, differences in linkage arrangements could account for the disparities. Breeding experiments are obviously required to distinguish between these or other explanations.

An association was also found between capitulum type and the number of seeds per capitulum. In all six populations the relative fitness of the radiate morph with respect to this character was greater than one, the average selective advantage being of the order of 30 per cent (table 4).

Richards (1975) calculated the reproductive potential of the two homozygous genotypes by multiplying the average number of capitula per plant by the average number of seeds per capitulum. This is not the total reproductive potential of the genotypes, however, as it takes no account of the length of the floweing period. If, for example, the radiate morph flowers for a much shorter period than the non-radiate morph, the total seed output of the two genotypes might be the same or the situation could be reversed, with the non-radiate morph being at an advantage. Until the length of the flowering period is measured in the field, calculations of instantaneous reproductive potentials are of little use.

Despite the apparent reproductive superiority shown by the radiate morph, no population has, as far as we are aware, reached fixation for the Tr allele. A lack of time for this to have occurred is probably not the explanation, for two reasons. First, the radiate morph was present in Cardiff, Penarth and in the surrounding district as early as 1892 (Trow, 1912) yet at Barry the populations are still polymorphic. Second, given the magnitude of the selective differences discussed above, the $\operatorname{Tr}$ allele should spread very rapidly through a population into which it has been introduced.

The lack of populations monomorphic for the radiate form suggests that other selective forces are operating against this genotype. It is possible that the flowering season of radiate plants is much shorter than that of nonradiate plants, thus neutralising or reversing their apparent reproductive advantage. Alternatively, selection may be acting on the vegetative 
differences between the morphs which Richards (1975) has identified. Whatever the forces involved in the maintenance of this polymorphism the data presented above indicates that there are marked differences in characters which could affect fitness between radiate and non-radiate morphs of groundsel. It is likely that the $\mathcal{T r}$ allele in $S$. vulgaris is serving as a marker for a number of other genes derived initially from $S$. squalidus. Where $S$. squalidus flourishes, presumably selection is favouring "squalidus-like" characters and under these conditions "squalidus-like" characters in $S$. vulgaris may also be at an advantage. Thus selection and not continued introgression is most probably resulting in the increase in the frequency of the $\operatorname{Tr}$ allele in the Edinburgh district where both species occur together (Hull 1975, 1976).

Acknowledgments.-Drs T. J. Crawford and A. H. Fitter and Mr B. R. Johnson kindly commented on drafts of this paper.

\section{References}

HULL, P. 1974a. Differences in esterase distribution detected by electrophoresis as evidence of continuing interspecific hybridisation in the genus Senecio. Ann. Bot., 38, 697-700.

HULL, P. 1974b. Self-fertilisation and the distribution of the radiate form of Senecio vulgaris L. in Central Scotland. Watsonia, 10, 69-75.

HULL, P. 1975. Selection and hybridisation as possible causes of changes in the frequency of alleles controlling capitulum type in Senecio vulgaris L. Watsonia, 11, 27-35.

HULL, P. 1976. The influences of different degrees of interspecific hybridisation with Senecio squalidus on the frequency of morphs of Senecio vulgaris. Heredity, 36, 67-72.

MONAGHAN, J. L., AND HULL, P. 1975. Differences in vegetative characteristics among four populations of Senecio vulgaris L., possibly due to interspecific hybridisation. Ann. Bot., $40,125-128$.

RICHARDS, A. J. 1975. The inheritance and behaviour of the rayed gene complex in Senecio vulgaris. Heredity, 34, 95-104.

TROW, A. H. 1912. On the inheritance of certain characters in the common groundsel, Senecio vulgaris L., and its segregates. F. Genet., 2, 239-276. 